\title{
Case Report \\ Giant Merkel Cell Carcinoma Masquerading as a Benign Cyst on the Buttock of an African American Man
}

\author{
Marissa J. Perman, Janelle M. King, Laurel L. Leithauser, and Hugh M. Gloster \\ Department of Dermatology, College of Medicine, University of Cincinnati, Cincinnati, OH 45267, USA \\ Correspondence should be addressed to Janelle M. King, king2jg@ucmail.uc.edu
}

Received 6 July 2011; Accepted 2 August 2011

Academic Editors: F. F. Attiyeh, J. M. Buchanich, and R. Yamamoto

Copyright ( $) 2011$ Marissa J. Perman et al. This is an open access article distributed under the Creative Commons Attribution License, which permits unrestricted use, distribution, and reproduction in any medium, provided the original work is properly cited.

\begin{abstract}
We report a case of a 60-year-old African American man who presented with a 4-year history of a previously asymptomatic, recently enlarging nodule on his left buttock, which was initially presumed to be an epidermoid cyst. Physical examination revealed a large, fixed, subcutaneous tumor, and a biopsy revealed merkel cell carcinoma. Immunohistochemical staining was positive for pankeratin, CAM 5.2, synaptophysin, and CD56 and negative for CK7, CK20, TTF-1, chromogranin, CD3, CD20, CD57, MART1, and HMB 45. The patient underwent wide local excision of the lesion with removal of the fascia overlying the gluteus and full body positron emission tomography (PET) and was found to have Stage IIb disease. He subsequently received adjuvant radiotherapy limited to the tumor bed at a dose of 60 gray.
\end{abstract}

\section{A Case Report}

A 60-year-old African American male presented with a 4-year history of an asymptomatic stable nodule involving the left buttock. The lesion was initially thought to be an epidermoid cyst that did not require treatment. However, he returned after the nodule rapidly increased in size over 2-3 months. Physical examination revealed a 9 by 10 centimeter fixed, subcutaneous tumor with overlying hyperpigmentation and slight scale (Figure 1).

A punch biopsy specimen demonstrated merkel cell carcinoma (MCC) (Figure 2). Immunohistochemistry stains were positive for pankeratin, CAM 5.2, synaptophysin, and CD56 and negative for CK7, CK20, TTF-1, chromogranin, CD3, CD20, CD57, MART1, and HMB 45. Full body positron emission tomography (PET) demonstrated uptake at the sight of the tumor and a local inguinal node. The patient underwent wide local excision of the mass with removal of the fascia overlying the gluteus. The underlying stripped muscle was grossly negative. The abnormal node on PET was identified as the sentinel lymph node and was negative, both by fine needle aspiration and excision. Upon pathologic review, the tumor involved only the deep margin. Therefore, he was diagnosed with Stage IIb MCC
(pT3N0M0). Given the positive deep margin, the patient subsequently received adjuvant radiotherapy limited to the tumor bed at a dose of 60 gray. Adjuvant chemotherapy was not indicated per National Comprehensive Cancer Network guidelines [1].

\section{Discussion}

MCC is an aggressive skin cancer usually noted on sun-exposed sites of elderly Caucasian men. The disease-associated mortality ranges from 33 to $50 \%$ [2, 3]. Merkel cells were initially believed to originate from neural crest-derived neuroendocrine cells; however, they are now thought to be derived from pluripotent epidermal stem cells [4]. Most MCC are likely induced by the merkel cell polyomavirus [3]. CK20 is the most frequently utilized immunohistochemical stain used to diagnose MCC and is positive in $89-100 \%$ of cases [1].

Key clinical characteristics of MCC include patient ethnicity, tumor location, and rate of tumor growth. The vast majority of patients $(\sim 98 \%)$ with MCC are white [2, $4,5]$. The most common tumor location involves the head and neck in sun-exposed regions. In addition, rapid rate of expansion ( $\leq 3$ months) is often associated with MCC [2]. 


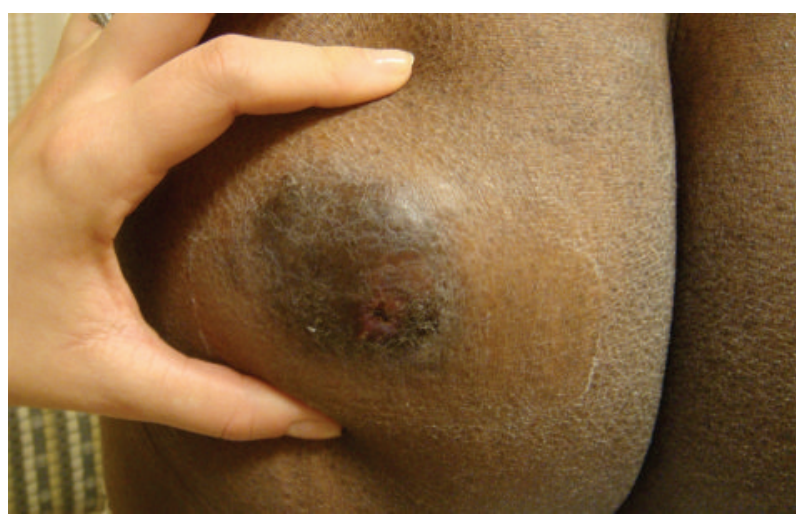

Figure 1: A 9 by 10 centimeter fixed, subcutaneous tumor with overlying hyperpigmentation and slight scale.

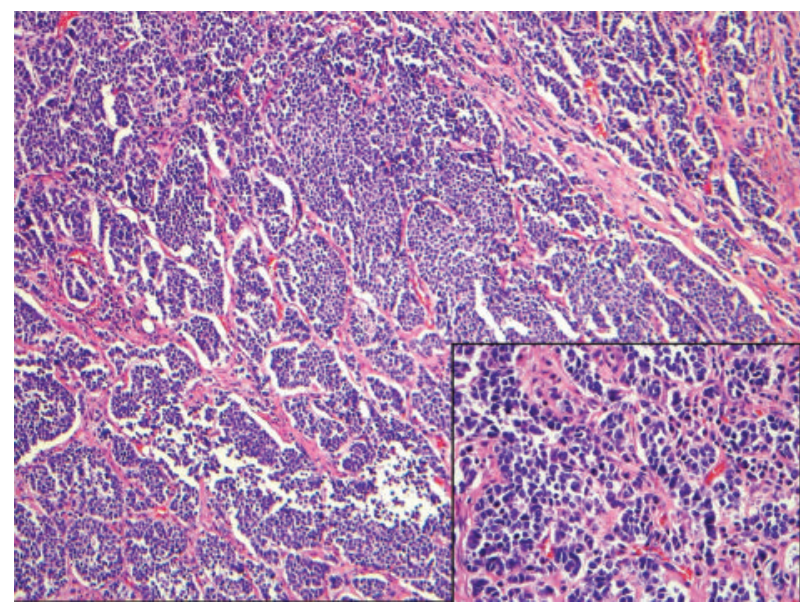

FIGURE 2: Ribbons of small, round, uniform blue cells with nuclear molding (hematoxylin-eosin, original magnification $\times 100$, inset: original magnification $\times 400$ ).

Immunosuppression is also a risk factor for MCC. Specifically, patients with human immunodeficiency virus, chronic lymphocytic leukemia, and solid organ transplantation are at increased risk for MCC [2].

We report an unusual presentation of MCC initially thought to be a benign slow growing cyst of the buttock in an otherwise healthy 60-year-old African American male. We highlight this case because of the patient's ethnicity, the length of time the tumor was present (four years) before the rapid growth phase, the non-sun-exposed primary site, and lack of immunosuppression. Furthermore, the tumor was relatively large $(9 \mathrm{~cm})$ and was negative for the CK 20 marker.

We aim to make dermatologists more aware of this unique presentation of a slow-growing giant MCC in a nonsun-exposed site of an African American patient.

\section{Conflict of Interests}

The authors have no conflict of interests to declare.

\section{References}

[1] "NCCN clinical practice guidelines in oncology: merkel cell carcinoma," National Comprehensive Cancer Network, Fort Washington, Pa, USA, 2010, http://www.nccn.org/professionals/physician_gls/PDF/mcc.pdf.

[2] M. Heath, N. Jaimes, B. Lemos et al., "Clinical characteristics of Merkel cell carcinoma at diagnosis in 195 patients: the AEIOU features," Journal of the American Academy of Dermatology, vol. 58, no. 3, pp. 375-381, 2008.

[3] K. G. Paulson, J. J. Carter, L. G. Johnson et al., "Antibodies to merkel cell polyomavirus $\mathrm{T}$ antigen oncoproteins reflect tumor burden in merkel cell carcinoma patients," Cancer Research, vol. 70, no. 21, pp. 8388-8397, 2010.

[4] J. A. Brown and B. R. Smoller, "Merkel cell carcinoma: what is it, what will it do and where will it go? What role should the pathologist play in reporting this information?" Journal of Cutaneous Pathology, vol. 36, no. 8, pp. 924-927, 2009.

[5] J. Albores-Saavedra, K. Batich, F. Chable-Montero, N. Sagy, A. M. Schwartz, and D. E. Henson, "Merkel cell carcinoma demographics, morphology, and survival based on 3870 cases: a population based study," Journal of Cutaneous Pathology, vol. 37, no. 1, pp. 20-27, 2010. 


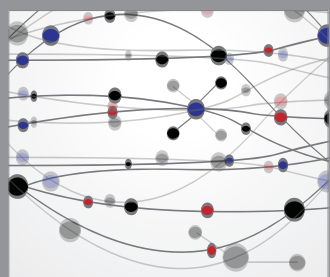

The Scientific World Journal
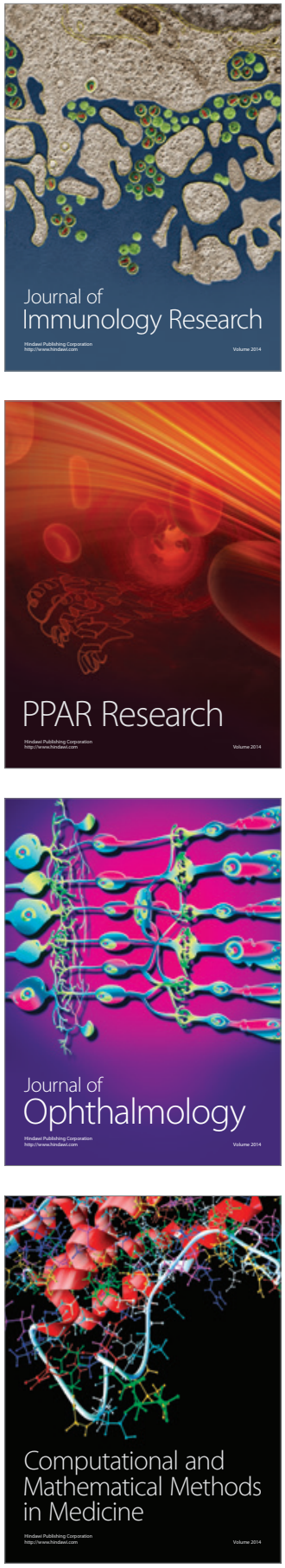

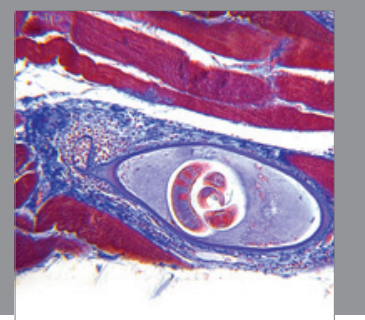

Gastroenterology

Research and Practice
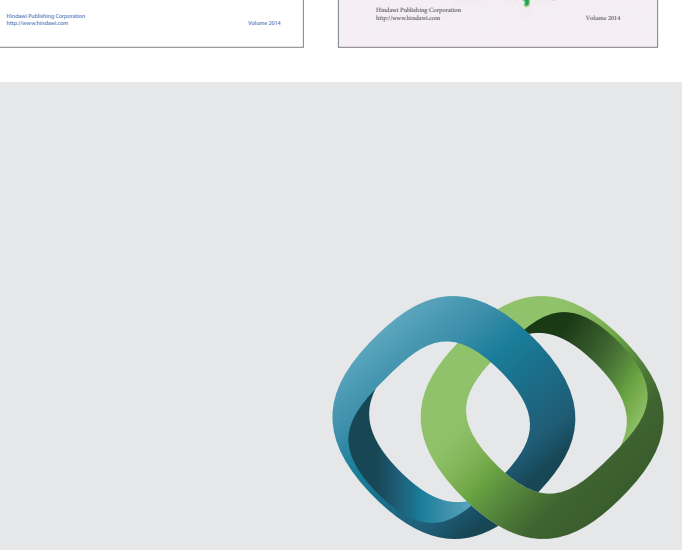

\section{Hindawi}

Submit your manuscripts at

http://www.hindawi.com
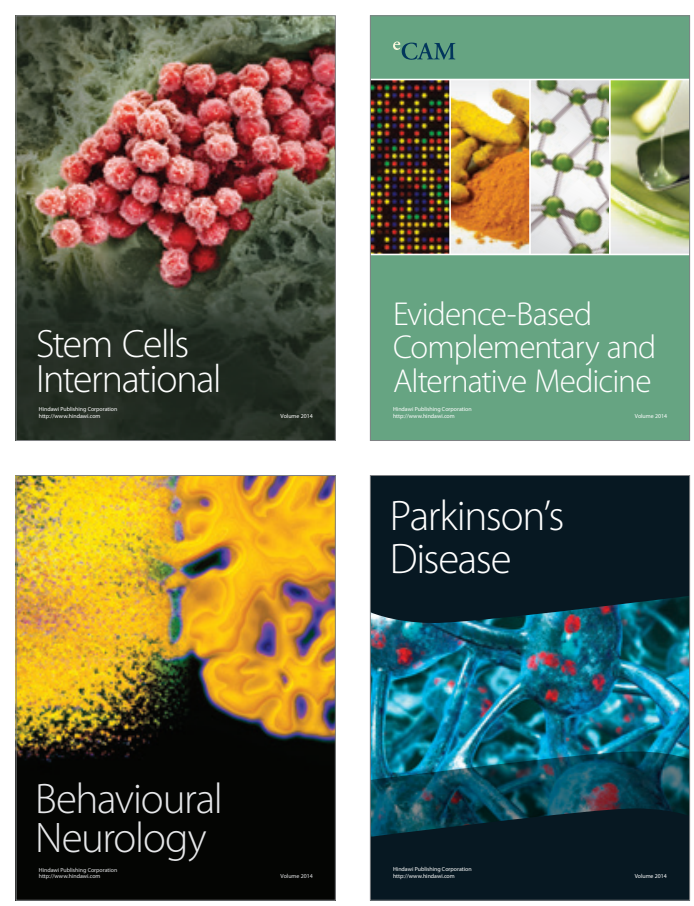

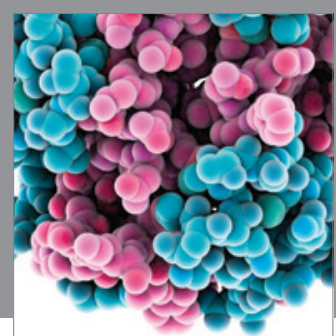

Journal of
Diabetes Research

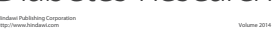

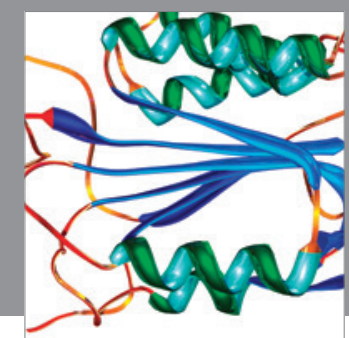

Disease Markers
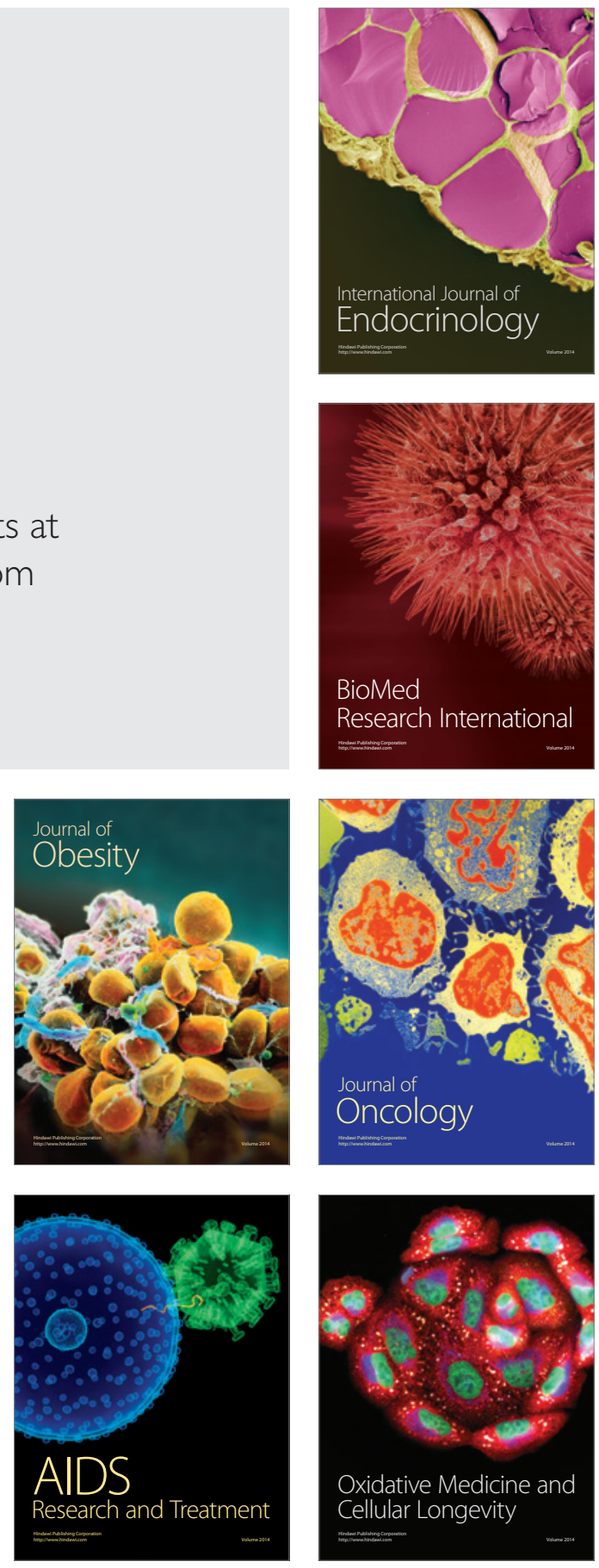